\title{
Detection of amyloid beta aggregates in the brain of BALB/c mice after Chlamydia pneumoniae infection
}

\author{
Ellen Boelen • Frank R. M. Stassen • André J. A. M. van der Ven • \\ Marijke A. M. Lemmens • Hellen P. J. Steinbusch • \\ Cathrien A. Bruggeman · Christoph Schmitz $\cdot$ Harry W. M. Steinbusch
}

Received: 12 March 2007 / Revised: 4 June 2007 / Accepted: 6 June 2007 / Published online: 21 June 2007

(C) Springer-Verlag 2007

\begin{abstract}
Neuroinflammation, initiated by cerebral infection, is increasingly postulated as an aetiological factor in neurodegenerative diseases such as Alzheimer's disease (AD). We investigated whether Chlamydia pneumoniae (Cpn) infection results in extracellular aggregation of amyloid beta $(\mathrm{A} \beta)$ in $\mathrm{BALB} / \mathrm{c}$ mice. At 1 week post intranasal infection (p.i.), Cpn DNA was detected predominantly in the olfactory bulbs by PCR, whereas brains at 1 and 3 months p.i. were $\mathrm{Cpn}$ negative. At 1 and 3 months p.i., extracellular $\mathrm{A} \beta$ immunoreactivity was detected in the brain of Cpn-infected mice but also in the brain of mockinfected mice and mice that were neither Cpn infected nor mock infected. However, these extracellular $\mathrm{A} \beta$ aggregates showed morphological differences compared to extracellular $\mathrm{A} \beta$ aggregates detected in the brain of transgenic $\mathrm{APP} 751^{\mathrm{SL}} / \mathrm{PS} 1^{\mathrm{M} 14 \mathrm{~L}}$ mice. These data do not unequivocally support the hypothesis that $\mathrm{Cpn}$ infection induces the formation of $\mathrm{AD}$-like $\mathrm{A} \beta$ plaques in the brain of $\mathrm{BALB} / \mathrm{c}$ mice, as suggested before. However, future studies are
\end{abstract}

E. Boelen $(\bowtie) \cdot$ F. R. M. Stassen · C. A. Bruggeman

Department of Medical Microbiology,

Cardiovascular Research Institute Maastricht (CARIM),

Maastricht University, PO Box 616, 6200 MD Maastricht,

The Netherlands

e-mail: Eboe@1mib.azm.nl

E. Boelen - M. A. M. Lemmens · H. P. J. Steinbusch .

C. Schmitz $\cdot$ H. W. M. Steinbusch

Department of Neuroscience, Maastricht University,

Maastricht, The Netherlands

\section{A. J. A. M. van der Ven}

Department of General Internal Medicine,

University Medical Centre St Radboud,

Nijmegen, The Netherlands required to resolve these differences and to investigate whether Cpn is indeed an etiological factor in AD pathogenesis.

Keywords Neuroinflammation Chlamydia pneumoniae . Amyloid-beta

\section{Introduction}

The most common cause of dementia is Alzheimer's disease (AD), which manifests in a familial and a sporadic form. The neuropathology in both conditions is characterized by neuritic or senile plaques, consisting mainly of amyloid beta protein $(\mathrm{A} \beta)$ and neurofibrillary tangles with hyperphosphorylated tau protein as its key components. Mutations in the amyloid precursor protein (APP), presenilin-1 (PS-1) or -2 (PS-2) genes have been associated with the familial form of AD [27]. However, the most common type of this disease, sporadic $\mathrm{AD}$, is not due to these mutations, and although risk factors have been identified, the initiating trigger is still unknown [18]. The potential importance of infections in the development of sporadic $\mathrm{AD}$ has been recently recognized $[1,21,31]$. Specifically, not only various viruses like the human immunodeficiency virus, herpes simplex virus and cytomegalovirus but also bacteria like Borrelia burgdorferi, have been linked to the process of neurodegeneration $[6,12,13,17,20]$. Some data also suggest that Chlamydia pneumoniae (Cpn) should be added to the list of pathogens possibly involved in the pathogenesis of $\mathrm{AD}$. Cpn is a widespread, obligatory intracellular pathogen, often causing acute respiratory infections including pneumonia, sinusitis and bronchitis $[10,11,15]$. This microorganism has also been implicated in a variety of severe, chronic diseases including some 
disorders of the central nervous system [7, 14, 30, 32]. In an initial study, Balin et al. demonstrated the presence of Cpn in brains of 17 out of 19 patients with sporadic AD, using a variety of techniques, including PCR, electron microscopy and immunohistochemistry, while the pathogen could only be demonstrated in 1 out of 19 controls [2]. The presence of $\mathrm{Cpn}$ was demonstrated in various cell types like microglia, astrocytes, perivascular macrophages and monocytes, and predominantly in brain areas linked with AD pathology. Recently, these observations were confirmed [8]. On the contrary, others were unable to detect $\mathrm{Cpn}$ in $\mathrm{AD}$ patient tissues [9, 22, 23, 28]. The only animal study so far supporting a role for this pathogen in $\mathrm{AD}$ demonstrated an AD-like pathology in the brain of BALB/c mice post Cpn infection [19]. Three-month-old mice were inoculated intranasally with $\mathrm{Cpn}$ and the authors claimed that this resulted in the deposition of $\mathrm{A} \beta$ in the brain up to 3 months post infection with increasing pathology as the infection progressed. Based on these results, it was concluded that in naïve $\mathrm{BALB} / \mathrm{c}$ mice, $\mathrm{AD}$ like pathology could be induced by Cpn infection. In spite of these results, doubts remain concerning the amyloidlike plaques as being only unrelated elevations in amyloid [24]. Because of the possible implications of this study and the need for confirmation, it was our aim to repeat these experiments under quite corresponding conditions. Moreover, we compared our findings with the pathology found in a transgenic mouse model of AD.

\section{Materials and methods}

\section{Chlamydia pneumoniae}

The Cpn strain, TWAR 2043 (ATCC) was cultured and continuously propagated on Hep2 cells as previously described [25]. Bacterial titres were determined by titration in Hep2 cells [7] and staining with a monoclonal Chlamydia LPS-specific antibody followed by a FITC-conjugated secondary antibody (RR-402; DAKO, Glostrup, Denmark). Titres were expressed as the number of inclusion forming units (IFU) per ml.
Animals and infection protocol

A total of 43 female, specific pathogen-free inbred BALB/c mice were obtained from Charles River (Someren, The Netherlands). Animals were kept under standard housing and care conditions at the Central Animal Facilities of Maastricht University (Maastricht, The Netherlands). All experimental procedures were approved by the Ethical Committee for the Use of Experimental Animals of Maastricht University.

At 3 months of age $n=24$ mice were inoculated intranasally with $10^{7}$ IFU Cpn in $10 \mu \mathrm{l}(5 \mu \mathrm{l}$ per nostril), and were analyzed at 1 week, 1 month or 3 months p.i., respectively, as shown in Table 1. Pilot experiments revealed that this dosage ensures both survival of the mice and optimal dissemination throughout the body. Another $n=15$ mice were mock infected with a sucrose-phosphate-glucose solution (SPG, solution for storage of Cpn) at 3 months of age and were also analyzed at 1 week, 1 month or 3 months after mock infection, as shown in Table 1. In addition, two mice, which did not receive any treatment, were investigated at 4 months of age, as well as two mice at 6 months of age (Table 1).

In addition, a 17-month-old transgenic mouse expressing human mutant APP751 (carrying the Swedish and London mutations KM670/671NL and V717I, under the Thy1 promoter) and human mutant presenilin-1 (PS-1 M146L, under the HMG promoter) was used (APP751 $1^{\mathrm{SL}} / \mathrm{PS}^{\mathrm{M} 146 \mathrm{~L}}$ mouse; for a detailed description see refs [4] and [24]) (Table 1). This APP751 ${ }^{\mathrm{SL}} / \mathrm{PS} 1^{\mathrm{M} 146 \mathrm{~L}}$ mouse was bred on a CBA $(12.5 \%) \times$ C57B16 $(87.5 \%)$ background.

Detection of Cpn DNA in brain tissue with real-time PCR

As shown in Table 1, 15 mice were used to detect Cpn DNA in brain tissue with real-time PCR at different time points after infection with Cpn or mock infection. To this end the animals received a weight-adjusted dose of pentobarbital (Nembutal; Sanofi Sante B.V., Maassluis, The Netherlands) and were then perfused with sterile phosphate buffered saline. Brains were removed quickly and dissected into five different regions, i.e., olfactory bulbs, cerebellum,

Table 1 Numbers of animals per group investigated in the present study

\begin{tabular}{|c|c|c|c|c|c|c|c|c|c|}
\hline \multirow[t]{2}{*}{ Mouse strain; analysis } & \multicolumn{3}{|c|}{ Infection with Cpn } & \multicolumn{3}{|c|}{ Mock infection } & \multicolumn{3}{|c|}{ No treatment } \\
\hline & $1 \mathrm{w}$ & $1 \mathrm{~m}$ & $3 m$ & $1 \mathrm{w}$ & $1 \mathrm{~m}$ & $3 \mathrm{~m}$ & M4 & M6 & M17 \\
\hline $\mathrm{BALB} / \mathrm{c} ; \mathrm{PCR}$ & 4 & 4 & 4 & 1 & 1 & 1 & - & - & - \\
\hline $\mathrm{BALB} / \mathrm{c} ; \mathrm{IHC}$ & - & 6 & 6 & - & 6 & 6 & 2 & 2 & - \\
\hline $\mathrm{APP} 751^{\mathrm{SL}} / \mathrm{PS} 1^{\mathrm{M} 146 \mathrm{~L}}$ & - & - & - & - & - & - & - & - & 1 \\
\hline
\end{tabular}

Cpn Chlamydia pneumoniae, IHC immunohistochemistry, $1 w / 1 \mathrm{~m} / 3 \mathrm{~m}$, analysis 1 week (or 1 month or 3 months, respectively) after Cpn infection or mock infection at 3 months of age. M4/M6/M17, 4, 6 or 17 months of age, respectively 
hippocampus, subventricular zone and neocortex. The isolated regions were snap-frozen in liquid nitrogen and stored at $-80^{\circ} \mathrm{C}$ until further processing.

DNA was isolated from brain material using methods previously described [5]. The Nanodrop ${ }^{\circledR}$ ND-1000, a fullspectrum spectrophotometer $(220-750 \mathrm{~nm})$ was used to calculate the DNA content of each sample. Finally, the Cpn DNA copy number/ $\mu \mathrm{g}$ DNA in the collected brains was determined by real-time PCR (ABI Prism 7000; Applied Biosystems, Foster City, CA, USA) using the following primers and probe; forward (5'TCCGCATTGCTCAGCC 3 '), reverse (5'AAACA ATTTGCATGAAGTCTGAGAA3') and probe (5'-FAM-TAAACTTAACTGCATGGAACCCTTC TTTACTAGG3'-T AMRA) as described previously [5, 29]. All PCR runs were performed in duplo. Mean Cpn DNA copy numbers/ $\mu$ g brain DNA of three independent experiments $( \pm$ SEM) was calculated. Then, comparisons between all groups of mice, analyzed for the presence of Cpn DNA in brain tissue, were performed with three-way ANOVA with Treatment (Cpn infection or mock infection), Timepoint of analysis (1 week, 1 month or 3 months p.i.) and Brain region (olfactory bulbs, cerebellum, hippocampus, subventricular zone or neocortex) as fixed factors. $P$ values smaller than 0.05 were considered statistically significant. Calculations were performed with SPSS v. 12.0.1 for Windows (SPSS, Chicago, IL, USA).

Detection of $A ß$ aggregates in brain tissue with immunohistochemistry

As also shown in Table $1, n=29$ mice were used to detect $\mathrm{A} \beta$ aggregates in brain tissue with immunohistochemistry at different time points after infection with Cpn, mock infection or without any treatment, respectively. To this end, the animals received a weight-adjusted dose of pentobarbital (Nembutal; Sanofi Sante B.V., Maassluis, The Netherlands) and were then subjected to intracardial perfusion fixation, as previously described [26]. In case of the APP751 $1^{\mathrm{SL}} / \mathrm{PS} 1^{\mathrm{M} 146 \mathrm{~L}}$ mouse, anaesthesia was performed with chloral hydrate $(10 \%$ aqueous solution, $0.005 \mathrm{ml} / \mathrm{g}$ body weight, i.p.). Brains were removed rapidly and post-fixed for $2 \mathrm{~h}$ at $4^{\circ} \mathrm{C}$ in the same fixative, omitting the glutaraldehyde. In case of the APP751 $1^{\mathrm{SL}} / \mathrm{PS} 1^{\mathrm{M} 146 \mathrm{~L}}$ mouse, the brains were halved in the midsagittal line. Brain tissues were then cryoprotected by immersion in $30 \%$ sucrose in Tris-buffered saline at $4^{\circ} \mathrm{C}$ overnight. Afterwards, brains (or brain halves, respectively) were quickly frozen and stored at $-80^{\circ} \mathrm{C}$ until further processing.

For immunohistochemical analysis, the entire brains (or the right brain half in case of the $\mathrm{APP} 751^{\mathrm{SL}} / \mathrm{PS} 1^{\mathrm{M} 146 \mathrm{~L}}$ mouse) were cut into entire series of 30- $\mu \mathrm{m}$-thick frontal sections on a cryostat (Leica CM 3050 S; Leica, Nussloch, Germany). After cutting, sections were again stored at $-80^{\circ} \mathrm{C}$ until further processing.
Immunohistochemical detection of $\mathrm{A} \beta$ (as well as of glial fibrillary acidic protein) was performed with standard immunofluorescence procedures using a first layer, consisting of a combination of mouse anti-human amyloid 17-24 (4G8 clone; 1:1,200 in TBS-T; Sigma-Aldrich, St Louis, USA) [3, $16,33]$ and polyclonal rabbit anti-mouse GFAP $(1: 1,600$ in TBS-T; DAKO, Glostrup, Denmark). The corresponding secondary antibodies were donkey anti-mouse Alexa 488 (1:100 in TBS-T; Molecular Probes) and donkey anti-rabbit Alexa 594 (1:100 in TBS-T; Molecular Probes). Finally, counterstaining was performed with Hoechst (1:500 in TBS; Sigma, St Louis, MO, USA) and sections were mounted on gelatine-coated glasses. As a negative control, sections were only incubated with the secondary antibodies.

Detection of extracellular $A ß$ aggregates in brain tissue with thioflavin-S

For the detection of extracellular, fibrillary $\mathrm{A} \beta$, a standard thioflavin-S (Sigma) staining was performed. Finally, the sections were counterstained with Hoechst and mounted as described above.

\section{Microscopy and photography}

Microscopic inspection of sections was performed with a MBF Bioscience Stereo Investigator Confocal Spinning Disk (SI-SD) system (MBF Bioscience; Williston, VT, USA), consisting of a modified Olympus BX51 fluorescence microscope (Olympus, Tokyo, Japan) with UPlanSApo objectives $10 \times($ N.A. $=0.4), 40 \times($ N.A $=0.9)$ and $100 \times($ oil; N.A = 1.4); Olympus, customized spinning disk unit (DSU; Olympus), computer-controlled excitation and emission filter wheels (Olympus), three-axis high-accuracy computer-controlled stepping motor specimen stage $(4 \times 4$ Grid Encoded Stage; Ludl Electronic Products, Hawthorne, NY, USA), linear $z$-axis position encoder (Ludl), ultra-high sensitivity monochrome electron multiplier CCD camera $(1,000 \times 1,000$ pixels, C9100-02; Hamamatsu Photonics, Hamamatsu City, Japan) and controlling software (MBF Bioscience). In case of sections processed for the detection of $A B$ and GFAP, digital RGB image stacks showing the same microscopic field in 50 consecutive focal planes with a distance of $0.5 \mu \mathrm{m}$ between the focal planes were generated with the $40 \times$ objective. In the case of sections stained with thioflavin-S, digital image stacks showing the same microscopic field at 150 consecutive RGB focal planes with a distance of $0.2 \mu \mathrm{m}$ between the focal planes were generated with the $100 \times$ objective. From these image stacks threedimensional reconstructions (maximum intensity projections) were produced with Imaris software (Version 4.0; Bitplane, Zurich, Switzerland). In addition, low-power photomicrographs $(10 \times)$ were taken from sections stained 
with thioflavin-S. Final figures were constructed using Corel Photo-Paint v.11 and Corel Draw v.11 (Corel, Ottawa, Canada). Only minor adjustments of contrast and brightness were made, without altering the appearance of the original materials. No deconvolution was performed on images obtained by confocal microscopy.

\section{Results}

Presence of Cpn in the brain of BALB/c mice infected with Cpn

At 1 week p.i., the mean Cpn DNA copy number per $\mu \mathrm{g}$ DNA was $310.97 \pm 61.6$ (mean \pm SEM) in the olfactory bulbs, $2.6 \pm 0.8$ in the cerebellum and $7.9 \pm 0.8$ in the hippocampus, while no Cpn DNA was detected in the subventricular zone and the neocortex (Table 2). No Cpn DNA was detected in any brain region of the $\mathrm{Cpn}$ infected mice at 1 and 3 months p.i.. Furthermore, Cpn DNA was not detected in the brain of mock-infected BALB/c mice at any time point. Statistical analysis revealed significant differences among the groups of mice with respect to Treatment (T) $(P=0.024)$, Time point of analysis (Tpoa) $(P=0.008)$ and Brain region $(\mathrm{Br})(P=0.002)$, as well as with respect to the combinations $\mathrm{T}-\mathrm{T}$ poa $(P=0.008), \mathrm{T}-\mathrm{Br}(P=0.002)$, Tpoa-Br $(P<0.001)$ and T-Tpoa-Br $(P<0.001)$.

Detection of $\mathrm{A} \beta$ and GFAP in the brain of BALB/c and APP751 ${ }^{\mathrm{SL}} / \mathrm{PS} 1^{\mathrm{M} 146 \mathrm{~L}}$ mice

Amyloid beta immunoreactivity was found in the brains of all mice, i.e. in Cpn-infected BALB/c mice at both 1 and 3 months p.i. (Fig. 1a), mock-infected BALB/c mice at both 1 and 3 months after mock infection (Fig. 1b), not inoculated BALB/c mice (Fig. 1c) and in APP751 $1^{\mathrm{SL}} / \mathrm{PS} 1^{\mathrm{M} 146 \mathrm{~L}}$ mice (Fig. 1d). However, $\mathrm{A} \beta$-immunopositive aggregates were found only occasionally in the brains of the BALB/c mice (on average one to two aggregates per section without

Table 2 Detection of Cpn DNA in various brain regions (olfactory bulbs, cerebellum, hippocampus, subventricular zone and neocortex) with real-time PCR at 1 week, 1 month and 3 months post infection

\begin{tabular}{llll}
\hline & 1 week p.i. & 1 month p.i. & 3 months p.i. \\
\hline Olfactory bulbs & $310.97 \pm 61.6$ & 0 & 0 \\
Cerebellum & $2.6 \pm 0.8$ & 0 & 0 \\
Hippocampus & $7.9 \pm 0.8$ & 0 & 0 \\
Subventricular & 0 & 0 & 0 \\
$\quad$ zone & 0 & 0 & 0 \\
Neocortex & 0 & 0
\end{tabular}

Data were expressed as mean values of three independent experiments \pm SEM a preference for a certain brain region), whereas they were found abundantly in hippocampus and neocortex of APP751 ${ }^{\mathrm{SL}} / \mathrm{PS} 1^{\mathrm{M} 146 \mathrm{~L}}$ mice (see also Fig. $2 \mathrm{H}$ in [24]). Furthermore, there were several qualitative differences between the APP751 $1^{\mathrm{SL}} / \mathrm{PS} 1^{\mathrm{M} 146 \mathrm{~L}}$ and the BALB/c mice. First, in the brain of APP751 $1^{\mathrm{SL}} / \mathrm{PS} 1^{\mathrm{M} 146 \mathrm{~L}}$ mice, the materials immunopositive for $\mathrm{A} \beta$ formed a dense core, devoid of Hoechst-positive structures (i.e. cell nuclei). In contrast, the materials immunopositive for $\mathrm{A} \beta$ in the brain of $\mathrm{BALB} / \mathrm{c}$ mice did not present with a dense core, and Hoechst-positive structures were scattered within these materials. Second, the astrocytic reaction in the brain of $\mathrm{APP} 751^{\mathrm{SL}} / \mathrm{PS} 1^{\mathrm{M} 146 \mathrm{~L}}$ mice, surrounding the $\mathrm{A} \beta$-immunopositive materials, was much stronger than in the brain of BALB/c mice (arrowheads in Fig. 1a-d). Third, in the brain of APP751 $1^{\mathrm{SL}} / \mathrm{PS} 1^{\mathrm{M} 146 \mathrm{~L}}$ mice, cells with intracellular deposits of $\mathrm{A} \beta$ were found (asterisk in Fig. 1d), which was not observed in the brain of BALB/c mice, irrespective of treatment.

Detection of thioflavin-S-positive structures in the brain of APP751 $1^{\mathrm{SL}} / \mathrm{PS} 1^{\mathrm{M} 146 \mathrm{~L}}$ but not in the brain of $\mathrm{BALB} / \mathrm{c}$ mice

In the brain of APP751 $1^{\mathrm{SL}} / \mathrm{PS} 1^{\mathrm{M} 146 \mathrm{~L}}$ mice, extracellular thioflavin-S-positive structures were found (Fig. 1e, f) as also previously reported $[4,26]$, resembling fibrillary $\mathrm{A} \beta$ deposits. Such extracellular thioflavin-S-positive structures were not found in the brain of BALB/c mice.

\section{Discussion}

The role of inflammatory factors, predominantly caused by infections, in the initiation or acceleration of neurodegenerative diseases is increasingly recognized. Next to several viruses [6, 12, 13, 17], the obligatory intracellular bacterium Cpn has also been linked to a variety of neurodegenerative diseases such as AD. In 1998, the presence of this pathogen was described in postmortem brains from patients with AD [2]. That Cpn may contribute to neurodegenerative processes was recently supported by data from our laboratory, as we demonstrated that $\mathrm{Cpn}$ is able to infect neurons, ultimately resulting in neuronal cell death in vitro [5]. However, to the best of our knowledge only one experimental in vivo study has been published so far supporting a role for Cpn in AD [19]. In this study, naïve BALB/c mice were inoculated intranasally with $\mathrm{Cpn}$ at an age of 3 months. Brains were recovered at 1-3 months p.i., revealing the presence of amyloid-like plaques and astrocyte reactivity. Due to the possible impact of this study, it was our goal to confirm these data by repeating these experiments. Focusing on our results of Cpn-inoculated mice at 3 months p.i., material immunopositive for $\mathrm{A} \beta$ was indeed 

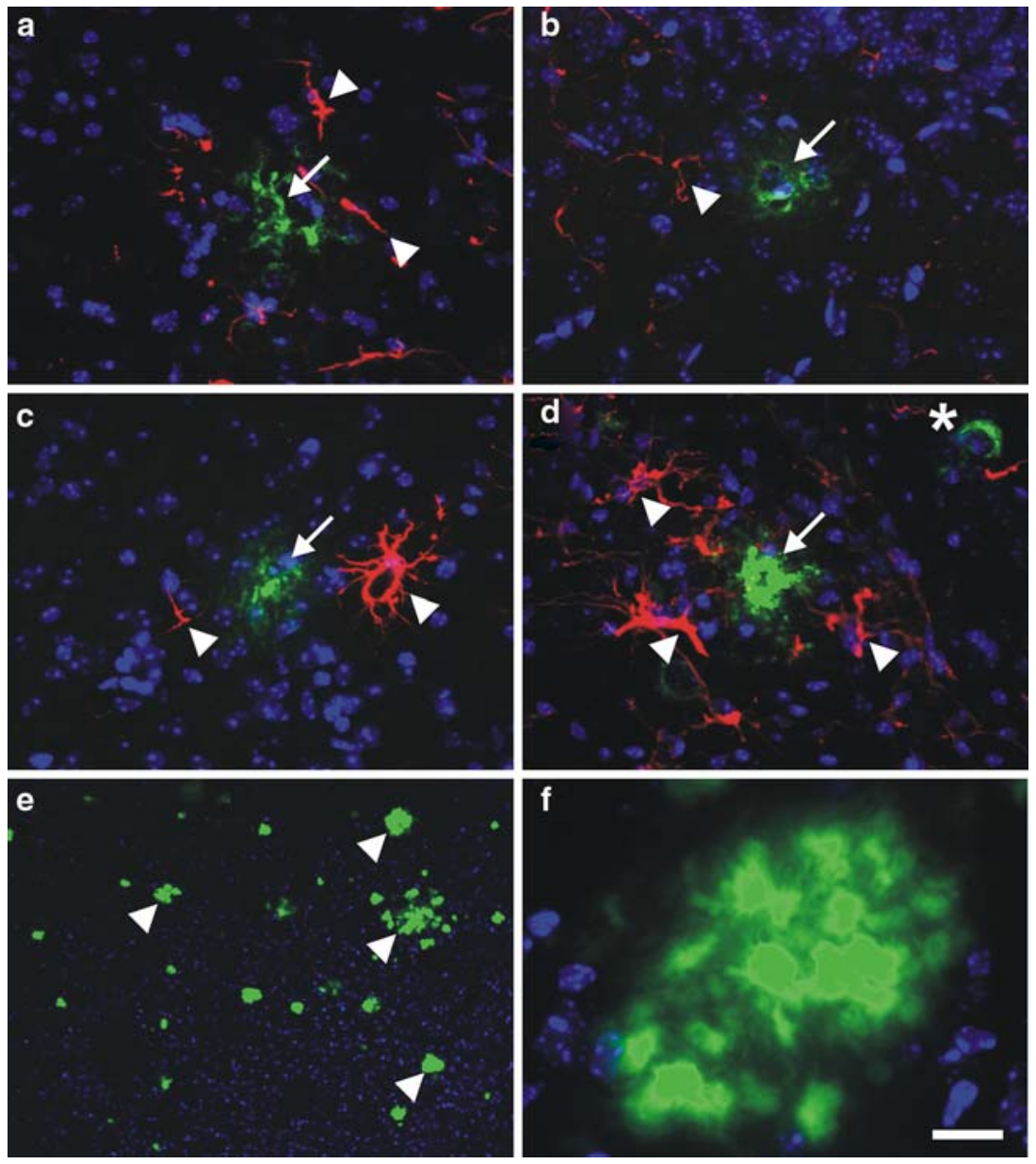

Fig. 1 Immunohistochemical detection of $\mathrm{A} \beta$ (green) and GFAP (red) in $30 \mu \mathrm{m}$-thick cryostat sections counterstained with Hoechst (blue) from the brain of a 6-month-old Cpn-infected BALB/c mouse 3 months post infection (a), a 6-month-old mock infected BALB/c mouse 3 months after mock infection (b), a 6-month-old BALB/c mouse neither infected with Cpn nor mock infected (c) and a 17month-old APP751 $1^{\mathrm{SL}} / \mathrm{PS} 1^{\mathrm{M} 146 \mathrm{~L}}$ transgenic mouse (d). Note that material immunopositive for $\mathrm{A} \beta$ was found in the brain of all mice (arrows). However, there were differences between the APP $751^{\mathrm{SL}} / \mathrm{PS} 1^{\mathrm{M} 146 \mathrm{~L}}$ mouse and the BALB/c mice: (1) in the brain of the $\mathrm{APP} 751^{\mathrm{SL}} /$ PS $1^{\mathrm{M} 146 \mathrm{~L}}$ mouse the material immunopositive for $\mathrm{A} \beta$ formed a dense core devoid of Hoechst-positive structures (i.e. cell nuclei). In contrast,

detected in the brain. Accordingly, at first glance, our results are in line with the study of Little et al. [19]. Comparing the morphological appearance of this material immunopositive for $\mathrm{A} \beta$ with corresponding material in the brain of $\mathrm{APP} 751^{\mathrm{SL}} / \mathrm{PS} 1^{\mathrm{M} 146 \mathrm{~L}}$ mice, however, some significant and important differences were observed. First, one characteristic of neuritic $(\mathrm{AD})$ plaques is the presence of filamentous, star-shaped aggregates of $\mathrm{A} \beta$ fibrils with a thioflavin-S-positive dense core. However, neither such star-shaped aggregates of $\mathrm{A} \beta$ fibrils nor extracellular thioflavin-S-positive structures were found in any of the brains of Cpn infected or mock infected BALB/c mice, whereas both lesions were abundant in the brain of $\mathrm{APP} 751^{\mathrm{SL}} /$

the material immunopositive for $\mathrm{A} \beta$ in the brain of the $\mathrm{BALB} / \mathrm{c}$ mice did not present with a dense core, and Hoechst-positive structures were scattered within it. (2) The astrocytic reaction in the brain of the APP $751^{\mathrm{SL}} / \mathrm{PS} 1^{\mathrm{M} 146 \mathrm{~L}}$ mouse surrounding the material immunopositive for $\mathrm{A} \beta$ was much stronger than in the brain of the $\mathrm{BALB} / \mathrm{c}$ mice (arrowheads). (3) In the brain of the APP751 ${ }^{\mathrm{SL}} / \mathrm{PS} 1^{\mathrm{M} 146 \mathrm{~L}}$ mouse cells with intracellular deposits of material immunopositive for $A B$ were found (asterisk in d). This was not observed in the brain of the BALB/ c mice. Furthermore, extracellular thioflavin-S-positive structures in the brain of the 17-month-old APP751 $1^{\mathrm{SL}} / \mathrm{PS} 1^{\mathrm{M} 146 \mathrm{~L}}$ mouse are shown [e (arrowheads) and f, resembling fibrillary $\mathrm{A} \beta$ deposits. Scale bar $=25 \mu \mathrm{m}$ in $\mathbf{a}-\mathbf{d}, 100 \mu \mathrm{m}$ in $\mathbf{e}$ and $10 \mu \mathrm{m}$ in $\mathbf{f}$

$\mathrm{PS}^{\mathrm{M} 146 \mathrm{~L}}$ mice. Second, no damage was found in the tissue surrounding the material immunopositive for $\mathrm{A} \beta$. Rather Hoechst-positive structures (i.e. cell nuclei) could be detected within the material immunopositive for $\mathrm{A} \beta$, a feature that was not seen in the brain of $\mathrm{APP} 751^{\mathrm{SL}} / \mathrm{PS} 1^{\mathrm{M} 146 \mathrm{~L}}$ mice. Finally, although astrocytes were found in the vicinity of the material immunopositive for $\mathrm{A} \beta$ in the brain of Cpn infected or mock infected BALB/c mice, they were not intimately associated with the $\mathrm{A} \beta$ immunoreactivity, as seen in the brain of APP751 $1^{\mathrm{SL}} / \mathrm{PS} 1^{\mathrm{M} 146 \mathrm{~L}}$ mice. In summary, except that $\mathrm{A} \beta$ plaques were detected in most brains, our data suggest that at 3 months after Cpn infection most characteristic features of AD pathology could not be detected in 
6-month-old naïve, non-transgenic BALB/c mice, whereas these were prominent in the brain of the "control" APP $751^{\mathrm{SL}} / \mathrm{PS} 1^{\mathrm{M} 146 \mathrm{~L}}$ mice. It may still be argued that the material immunopositive for $\mathrm{A} \beta$ in the brain of the Cpninfected mice represented early precursors of neuritic plaques. To our surprise, however, nearly identical patterns of $\mathrm{A} \beta$ immunoreactivity were detected in mock-infected $\mathrm{BALB} / \mathrm{c}$ mice as well as in BALB/c mice, neither Cpn infected nor mock infected. This suggests that the observed immunoreactivity for $\mathrm{A} \beta$ in the brain of $\mathrm{BALB} / \mathrm{c}$ mice does not directly result from $\mathrm{Cpn}$ infection but might represent unrelated elevations in amyloid. Positive staining for $\mathrm{A} \beta$ in the brain of mock-infected mice was also observed by Little et al. [19], who found that the amyloid deposition load and size were significantly enhanced in Cpn-infected mice compared to mock infected ones. As outlined above, this was not found in the present study. Furthermore, Little et al. also demonstrated the presence of a small subset of thioflavin-S positive plaques, which were not found in our mice. These discrepancies between the study by Little et al. [19] and the present study could be due to the fact that Little et al. [19] used a Cpn strain (C. pneumoniae, 96-41, isolated from the postmortem brain of an $\mathrm{AD}$ patient) that was rather different from the $\mathrm{Cpn}$ strain used in the present study (TWAR 2043, ATCC). Notably, Little et al. [19], were able to detect $\mathrm{Cpn}$ in olfactory tissues of infected mice up to 3 months p.i., by both light and electron microscopy. In the present study, however, we were only able to detect Cpn DNA in the olfactory bulb of infected BALB/c mice at 1 week p.i. but not at 1 or 3 months p.i., despite the use of a more sensitive detection method (real-time PCR). As it is well established that the clinical isolates of pathogens are often more infectious than their laboratory counterparts, this could partially explain the discrepancy between both studies. Furthermore, it cannot be excluded that differences in solutions used for mock infection (Hanks balanced salt solution in the study by Little et al. [19] vs. SPG solution in the present study) may have affected the final outcome. Yet, in the present study, the immunosignal in mice that were neither Cpn infected nor mock infected appeared somewhat weaker than in the brain of the BALB/c mice that were either Cpn- or mock-infected (a detailed quantitative analysis was not performed). This suggests that intranasal application of $\mathrm{Cpn}$ or other infectious agents may trigger the production and deposition of $\mathrm{A} \beta$ in the brain of $\mathrm{BALB} / \mathrm{c}$ mice. For the time being, however, the impact of this remains unclear.

In conclusion, our data do not unequivocally support the hypothesis that $\mathrm{Cpn}$ infection induces the formation of $\mathrm{AD}$ like $\mathrm{A} \beta$ plaques in the brain of $\mathrm{BALB} / \mathrm{c}$ mice, as suggested by Little et al. [19]. Accordingly, future studies are required to investigate whether $\mathrm{Cpn}$ infections may aggravate $\mathrm{AD}$ pathology by stimulating the formation of $\mathrm{A} \beta$ plaques as has been suggested in atherosclerosis, a disease that is also characterized by pronounced local inflammation.

Acknowledgments We thank Sofie Lemmens for excellent technical assistance. This study was supported by grants from the International Alzheimer's Research Foundation (ISAO; The Netherlands) and the Netherlands Organization for Scientific Research (NWO; The Netherlands).

\section{References}

1. Balin BJ, Appelt DM (2001) Role of infection in Alzheimer's disease. J Am Osteopath Assoc 101:S1-S6

2. Balin BJ, Gerard HC, Arking EJ, Appelt DM, Branigan PJ, Abrams JT, Whittum-Hudson JA, Hudson AP (1998) Identification and localization of Chlamydia pneumoniae in the Alzheimer's brain. Med Microbiol Immunol (Berl) 187:23-42

3. Bhatia R, Lin H, Lal R (2000) Fresh and globular amyloid beta protein (1-42) induces rapid cellular degeneration: evidence for AbetaP channel-mediated cellular toxicity. FASEB J 14:1233-1243

4. Blanchard V, Moussaoui S, Czech C, Touchet N, Bonici B, Planche M, Canton T, Jedidi I, Gohin M, Wirths O, Bayer TA, Langui D, Duyckaerts C, Tremp G, Pradier L (2003) Time sequence of maturation of dystrophic neurites associated with Abeta deposits in APP/PS1 transgenic mice. Exp Neurol 184:247-263

5. Boelen E, Steinbusch HW, van der Ven AJ, Grauls G, Bruggeman CA, Stassen FR (2007) Chlamydia pneumoniae infection of brain cells: an in vitro study. Neurobiol Aging 28(4):524-532

6. Dobson CB, Itzhaki RF (1999) Herpes simplex virus type 1 and Alzheimer's disease. Neurobiol Aging 20:457-465

7. Ezzahiri R, Stassen FR, Kurvers HA, van Pul MM, Kitslaar PJ, Bruggeman CA (2003) Chlamydia pneumoniae infection induces an unstable atherosclerotic plaque phenotype in LDL-receptor, ApoE double knockout mice. Eur J Vasc Endovasc Surg 26:88-95

8. Gerard HC, Dreses-Werringloer U, Wildt KS, Deka S, Oszust C, Balin BJ, Frey WH II, Bordayo EZ, Whittum-Hudson JA, Hudson AP (2006) Chlamydophila (Chlamydia) pneumoniae in the Alzheimer's brain. FEMS Immunol Med Microbiol 48:355-366

9. Gieffers J, Reusche E, Solbach W, Maass M (2000) Failure to detect Chlamydia pneumoniae in brain sections of Alzheimer's disease patients. J Clin Microbiol 38:881-882

10. Grayston JT, Campbell LA, Kuo CC, Mordhorst CH, Saikku P, Thom DH, Wang SP (1990) A new respiratory tract pathogen: Chlamydia pneumoniae strain TWAR. J Infect Dis 161:618-625

11. Grayston JT, Aldous MB, Easton A, Wang SP, Kuo CC, Campbell LA, Altman J (1993) Evidence that Chlamydia pneumoniae causes pneumonia and bronchitis. J Infect Dis 168:1231-1235

12. Hemling N, Roytta M, Rinne J, Pollanen P, Broberg E, Tapio V, Vahlberg T, Hukkanen V (2003) Herpesviruses in brains in Alzheimer's and Parkinson's diseases. Ann Neurol 54:267-271

13. Kolson DL, Gonzalez-Scarano F (2000) HIV and HIV dementia. J Clin Invest 106:11-13

14. Kuo CC, Grayston JT, Campbell LA, Goo YA, Wissler RW, Benditt EP (1995) Chlamydia pneumoniae (TWAR) in coronary arteries of young adults (15-34 years old). Proc Natl Acad Sci USA 92:6911-6914

15. Kuo CC, Jackson LA, Campbell LA, Grayston JT (1995) Chlamydia pneumoniae (TWAR). Clin Microbiol Rev 8:451-461

16. Law A, Gauthier S, Quirion R (2001) Say NO to Alzheimer's disease: the putative links between nitric oxide and dementia of the Alzheimer's type. Brain Res Brain Res Rev 35:73-96

17. Lin WR, Wozniak MA, Cooper RJ, Wilcock GK, Itzhaki RF (2002) Herpesviruses in brain and Alzheimer's disease. J Pathol 197:395-402 
18. Lippa CF, Saunders AM, Smith TW, Swearer JM, Drachman DA, Ghetti B, Nee L, Pulaski-Salo D, Dickson D, Robitaille Y, Bergeron C, Crain B, Benson MD, Farlow M, Hyman BT, George-Hyslop SP, Roses AD, Pollen DA (1996) Familial and sporadic Alzheimer's disease: neuropathology cannot exclude a final common pathway. Neurology 46:406-412

19. Little CS, Hammond CJ, MacIntyre A, Balin BJ, Appelt DM (2004) Chlamydia pneumoniae induces Alzheimer-like amyloid plaques in brains of BALB/c mice. Neurobiol Aging 25:419-429

20. MacDonald AB (2006) Plaques of Alzheimer's disease originate from cysts of Borrelia burgdorferi, the Lyme disease spirochete. Med Hypotheses 67:592-600

21. Mattson MP (2004) Infectious agents and age-related neurodegenerative disorders. Ageing Res Rev 3:105-120

22. Nochlin D, Shaw CM, Campbell LA, Kuo CC (1999) Failure to detect Chlamydia pneumoniae in brain tissues of Alzheimer's disease. Neurology 53:1888

23. Ring RH, Lyons JM (2000) Failure to detect Chlamydia pneumoniae in the late-onset Alzheimer's brain. J Clin Microbiol 38:2591-2594

24. Robertson M (2004) Is Chlamydia associated with Alzheimer's? Drug Discov Today 9:469

25. Roblin PM, Dumornay W, Hammerschlag MR (1992) Use of HEp-2 cells for improved isolation and passage of Chlamydia pneumoniae. J Clin Microbiol 30:1968-1971
26. Schmitz C, Rutten BP, Pielen A, Schafer S, Wirths O, Tremp G, Czech C, Blanchard V, Multhaup G, Rezaie P, Korr H, Steinbusch HW, Pradier L, Bayer TA (2004) Hippocampal neuron loss exceeds amyloid plaque load in a transgenic mouse model of Alzheimer's disease. Am J Pathol 164:1495-1502

27. Tanzi RE, Kovacs DM, Kim TW, Moir RD, Guenette SY, Wasco W (1996) The gene defects responsible for familial Alzheimer's disease. Neurobiol Dis 3:159-168

28. Taylor GS, Vipond IB, Paul ID, Matthews S, Wilcock GK, Caul EO (2002) Failure to correlate C. pneumoniae with late onset Alzheimer's disease. Neurology 59:142-143

29. Tondella ML, Talkington DF, Holloway BP, Dowell SF, Cowley K, Soriano-Gabarro M, Elkind MS, Fields BS (2002) Development and evaluation of real-time PCR-based fluorescence assays for detection of Chlamydia pneumoniae. J Clin Microbiol 40:575-583

30. Weinberger M (2004) Respiratory infections and asthma: current treatment strategies. Drug Discov Today 9:831-837

31. Wucherpfennig KW (2002) Infectious triggers for inflammatory neurological diseases. Nat Med 8:455-457

32. Yucesan C, Sriram S (2001) Chlamydia pneumoniae infection of the central nervous system. Curr Opin Neurol 14:355-359

33. Zhu YJ, Lin H, Lal R (2000) Fresh and nonfibrillar amyloid beta protein (1-40) induces rapid cellular degeneration in aged human fibroblasts: evidence for AbetaP-channel-mediated cellular toxicity. FASEB J 14:1244-1254 